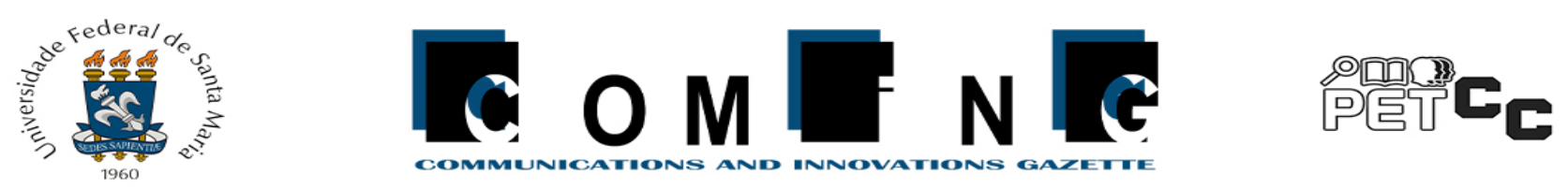

\title{
Proposta de dispositivo de baixo custo para monitoramento da qualidade da água
}

\author{
Marco Antonio Barbosa Castro ${ }^{1}$, Marco Antônio Alchaar Guimarães ${ }^{1}$, \\ Gustavo Henrique Barbosa de Oliveira ${ }^{1}$, Rogério Starich Silva ${ }^{2}$, \\ Mauro Lúcio Franco ${ }^{2}$
}

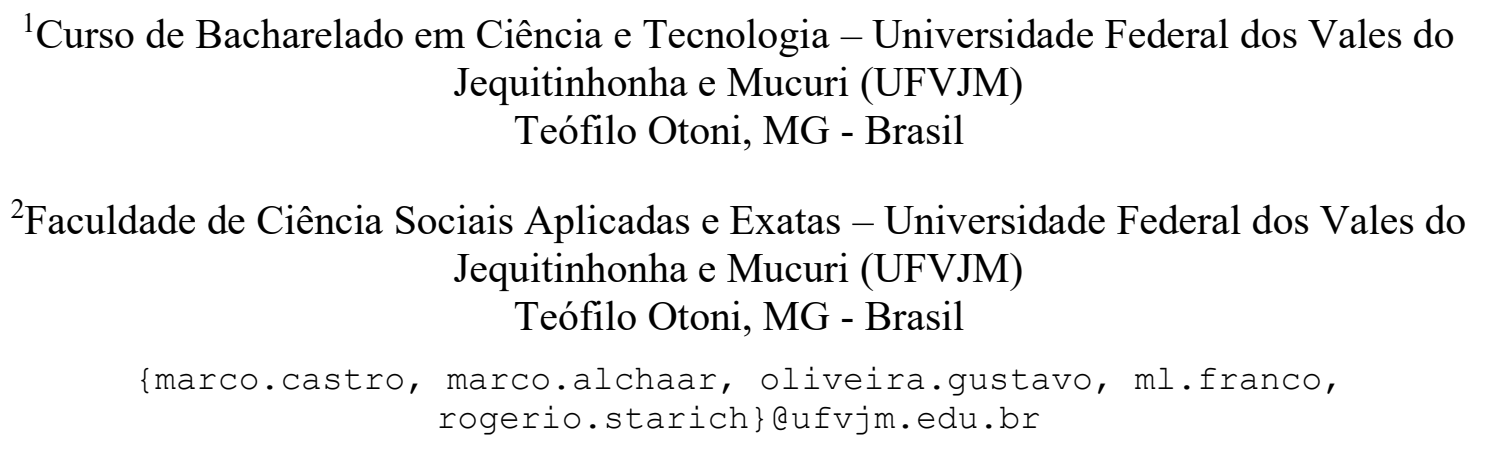

\begin{abstract}
Water is one of the most substantial resources for continuity of life on Earth. Therefore, the conservation of its quality for human consumption is essential, not only for maintenance of health but also for the minimum conditions of survival. However, Brazil still has a deficit in the public basic sanitation system, mainly with regard to the distribution and control of the quality of the water that supplies homes. Thus, in order to minimize part of these problems this project aims to develop two low-cost sensors (Turbidity and Conductivity) for studying and monitoring water using an Arduino platform.
\end{abstract}

\begin{abstract}
Resumo. A água é um dos recursos mais importantes para a continuidade da vida no planeta Terra. Portanto, a conservação da sua qualidade para o consumo humano é fundamental não só para a manutenção da saúde, como também das condições mínimas de sobrevivência. Contudo, o Brasil ainda apresenta um déficit no sistema público de saneamento básico principalmente no que se diz respeito a distribuição e controle da qualidade da água que abastece as residencias. Dessa maneira, como forma de minimizar parte desses problemas, este trabalho tem por finalidade o desenvolvimento de dois sensores de baixo custo (Turbidez e de Condutividade) para o estudo e monitoramento da água, utilizando a plataforma Arduino.
\end{abstract}

\section{Introdução}

A qualidade da água está diretamente ligada a seus componentes e as suas concentrações, de tal forma que a classificação de pureza e potabilidade da água é embasada na quantidade desses elementos (BRASIL, 2014). Dessa forma, a análise dos aspectos físicoquímicos e biológicos da água são realizados por meio de diversos testes em laboratórios, 
que utilizam equipamentos de custo elevado e manuseio complexo, o que os tornam inacessíveis para o uso doméstico.

Além disso, de acordo com Ministério da Saúde (2006): “[..] tem-se verificado que a qualidade da água decai no sistema de distribuição pela intermitência do serviço, pela baixa cobertura da população com sistema público de esgotamento sanitário, obsolescência da rede de distribuição, manutenção deficiente, entre outros. Nos domicílios, os níveis de contaminação elevam-se devido a precariedade das instalações hidráulico-sanitárias, pela falta de manutenção dos reservatórios e manuseio inadequado da água." Ademais, de acordo com Filho (2016), mesmo com o avanço significativo em relação a infraestrutura de abastecimento público de água, proveniente ao atendimento com coleta e tratamento de esgotos, há ainda lacunas em algumas áreas urbanizadas no que diz respeito aos déficits de atendimento desses serviços para a população.

Essa precariedade do sistema de saneamento básico, bem como a falha na preservação de recursos hídricos, se comprova em diversos rios e córregos pelo Brasil, tais como o rio Tiete na cidade de São Paulo, Baía de Guanabara no Rio de Janeiro e no rio Todos os Santos, principal responsável pelo abastecimento de água na cidade de Teófilo Otoni, cidade na qual a Universidade Federal dos Vales do Jequitinhonha e Mucuri (UFVJM), campus do Mucuri está localizada. (VESPERMANN, 2012).

Sendo assim, de que forma a utilização de sensores de baixo custo podem ajudar no monitoramento da qualidade da água nas residências? Os sensores de turbidez e condutividade de baixo custo permitem ao usuário identificar as possíveis alterações e variância em relação ao padrão normal de abastecimento de água nas residências, bem como, identificar períodos nos quais houve falta de abastecimento. Dessa forma, esses sensores estão sendo desenvolvidos e testados pela equipe de pesquisa em robótica e Arduíno do Programa de Educação Tutorial - PET Novas Tecnologias Voltadas para o Ensino.

O trabalho pode ser justificado como parte das políticas públicas visando à inclusão social e o desenvolvimento sustentável. A região do Vale do Mucuri situada no nordeste de Minas Gerais, tem um dos mais baixos indicadores socioeconômicos do País e problemas de origem hídrica. A socialização desses conhecimentos, torna-se relevante aos nossos petianos uma vez que: contribui para melhoraria da compreensão dos conteúdos acadêmicos estudados, do mundo que os cerca, bem como suas modificações sociais decorrentes. A pesquisa está em desenvolvimento de acordo com o sequenciamento metodológico desenvolvido pelo grupo PET.

\section{Trabalhos Relacionados}

Há diversos trabalhos na literatura que abordam a questão do monitoramento da qualidade da água por meio de uma plataforma Arduino e sensores conectados ao dispositivo. Alguns desses trabalhos, serviram de base para a presente pesquisa. Dentre os quais podemos citar Oliveira (2015), Lima (2018), Gillett e Marchiori (2019) e Mesa et al. (2015). 
Oliveira (2015), que discorre sobre a análise e o desenvolvimento de dois sensores de turbidez de baixo custo, utilizando-se fonte de luz visível (LED de cor branca) em um dos módulos e fonte de luz infravermelha (LED infravermelho) em outro.

O trabalho de Lima (2018) consiste em um "módulo de sensores para monitoramento da qualidade da água com transmissão sem fio utilizando plataforma de prototipagem". A proposta inicial, consistia no monitoramento de alguns aspectos da água fornecida a Universidade Estadual de Feira de Santana, e futuramente ampliar para outros campos de atuação como rios, lagoas, água da chuva, ou reuso, utilizando sensores comerciais.

David Gillett e Alan Marchiori (2019) desenvolveram um sensor de turbidez de baixo custo, com dispêndio de aproximadamente 64 dólares. O sensor é constituído por um LED branco de alto brilho e dois sensores de luz ambiente (TSL4531 light sensor) anexados no exterior de um cano transparente, um a $180^{\circ}$ e outro a $90^{\circ}$ do LED. O sensor foi calibrado na escala nefelométrica (NTU) com precisão de 1 NTU. Contudo, após um certo período notou-se a necessidade de calibragem periódica no sensor devido a divergências em todas as leituras.

Correspondente às ideias citadas, há ainda o trabalho de Mesa et al. (2015), cujo objetivo consistiu no desenvolvimento do Waterlife que "é um dispositivo construído com sensores que podem medir os fatores físico-químicos da água, ajudando na prevenção de futuros danos que podem ser causados caso a água não se encontre dentro dos valores padrões de potabilidade". O trabalho consistiu na utilização de sensores comerciais de pH e temperatura, além do desenvolvimento de sensores de condutividade e turbidez de baixo custo.

Os trabalhos relacionados citados na pesquisa, possuem como finalidade a construção de um sistema que seja de baixo custo e tão eficiente quanto os produtos já comercializados para esse fim: como testadores, eletrodos, medidores, bem como, o monitoramento da qualidade da água. Contudo, não possuem como objetivo a instalação em residências como forma do usuário identificar as possíveis alterações e variância em relação ao padrão normal de abastecimento de água.

\section{Qualidade da Água}

A água é a fonte de vida, ou seja, a sua importância é de tamanha proporção, visto que é um elemento imprescindível para o surgimento e sobrevivência de toda forma de vida. Além de ser um recurso natural essencial, não só para a composição bioquímica dos seres vivos e meio de vida para muitas espécies, serve também como matéria prima para a produção de diversos produtos de consumo de grande relevância para a sociedade (MIERZWA, 2002).

Contudo, ainda que de extrema importância para a vida humana, as pessoas e, principalmente indústrias, permanecem poluindo rios, lagos e oceanos, alterando suas características físicas e bioquímicas. Estas mudanças não só tornam o ecossistema 
aquático inadequado para o surgimento de fauna e flora como também aumentam o custo para tornar a água própria para o consumo humano (PALUDO, 2010).

A água geralmente contém diversos componentes, os quais provêm do próprio ambiente natural ou foram introduzidos a partir de atividades humanas. A qualidade da água está diretamente ligada a esses componentes e a suas concentrações, de tal forma que, a classificação de pureza e potabilidade da água é embasada na quantidade desses componentes (BRASIL, 2014). Os aspectos físico-químicos e biológicos, da água são analisados por meio de diversos testes realizados em laboratórios.

Conforme a norma de potabilidade da água do Ministério da Saúde (BRASIL, 2011), também conhecida como a Portaria da potabilidade da água, é recomendado a análise de parâmetros físicos, químicos e biológicos, sendo eles:

- Físicos: cor, turbidez, temperatura, radioatividade, condutividade;

- Organolépticos: gosto e odor;

- Químicos: pH, cloraminas, dióxido de cloro, cloro residual livre, fluoreto, agrotóxicos, produtos secundários da desinfecção, cianotoxinas;

- Microbiológicos: coliformes totais, Escherichia coli;

- Hidrobiológicos: cianobactérias;

Desse modo, os parâmetros estabelecidos por esta portaria devem ser respeitados pelos responsáveis pelo tratamento e fornecimento de água, portanto, garantindo a qualidade e segurança do seu consumo à população.

\subsection{Turbidez}

Conforme Cardoso (2011), a turbidez pode ser entendida como a diminuição da intensidade de um feixe de luz ao atravessar uma amostra de água. Essa variação à penetração da luz na água é ocasionada pela presença de materiais em suspensão que obstruem a passagem de alguns raios de luz.

De acordo com a Portaria de Potabilidade da Água, os altos índices de turbidez podem acarretar o aumento do uso de produtos químicos e, consequentemente, ocasionar um aumento no custo de tratamento, esse por sua vez, refletindo na conta de água do consumidor. Além disso, a turbidez é um padrão organoléptico, ou seja, característica que pode ser notada pelos cinco sentidos humanos, sendo comumente utilizada pela população para analisar e categorizar a qualidade da água de recebimento.

O equipamento utilizado para medição da turbidez, é denominado turbidímetro. Conforme o manual do turbidímetro portátil HI98703 da Hanna Instruments, "o instrumento foi especialmente desenvolvido para medições de qualidade da água, fornecendo uma leitura precisa e confiável de valores de turbidez baixa". Contudo, devido ter sido desenvolvido para fins laboratoriais e manuseio complexo, acaba apresentando um preço elevado inacessível para a maioria da população. Além disso, não é possível realizar análises em tempo real devido à necessidade de calibração sempre que iniciado, como também de amostras colhidas de água. 


\subsection{Condutividade Elétrica da Água}

A condutividade elétrica, indica a capacidade de uma substância conduzir corrente elétrica devido a presença de substâncias iônicas dissolvidas que, ao interagirem com água, se dissociam em cátions e ânions. Em outras palavras, corresponde a facilidade ou dificuldade da passagem de eletricidade através da água (BRASIL, 2006).

O valor da condutividade elétrica está diretamente ligado a concentração iônica da solução, sendo assim, ao realizar a medida da condutividade elétrica de uma amostra, indiretamente, está realizando a verificação da presença de íons, geralmente substâncias inorgânicas, tais como cloretos, sulfatos, sódio, cálcio, ferro e alumínio. Dessa forma, a presença de tais elementos resulta no aumento da condutividade elétrica, contudo, caso a amostra contenha materiais orgânicos dissolvidos, como óleos, graxas e álcool a condutividade elétrica diminuiu devido a incapacidade desses materiais em conduzir eletricidade (AGSOLVE, 2013).

Observa-se que a condutividade na água depende de vários fatores, dessa forma, qualquer mineral dissolvido na água pode alterar o valor da medida e, por esse motivo, é difícil estabelecer um valor padrão para esta característica físico-química. Discrepâncias na medida do valor da condutividade, são fortes indicativos de irregularidades no abastecimento.

No Sistema Internacional de Unidades a condutividade elétrica é expressa em Siemens por metro $(\mathrm{S} / \mathrm{m})$, contudo, em medidas realizadas em água é empregado microSiemens $(\mu \mathrm{S} / \mathrm{cm})$ ou miliSiemens por centímetro $(\mathrm{mS} / \mathrm{cm})(\mathrm{CPRM}-$ Serviço Geológico do Brasil, 2007).

A condutividade elétrica é medida por meio da utilização de um aparelho denominado condutivímetro. Apesar deste equipamento ser de manuseio mais fácil que o turbidímetro, também apresenta um custo elevado.

Ademais, a condutividade elétrica pode ser utilizada para qualificar substâncias conforme a sua capacidade de conduzir corrente elétrica, em vista disso, uma ótima aplicação para essa propriedade é a diferenciação da condutividade entre a água potável e o ar, pois este último, apresenta a uma condutividade bem menor em comparação.

\subsection{Abastecimento de água}

Os fornecedores de água são os responsáveis por manter a qualidade da água dentro dos padrões estabelecidos pela Portaria n ${ }^{\circ} 2.914$, de 12 de dezembro de 2011 b.

$\mathrm{Na}$ estação de tratamento de água (ETA), a água passa por diversos processos físicos e químicos, nos quais, os parâmetros de potabilidade são ajustados conforme os estabelecidos pelo Ministério da Saúde. Ao decorrer desses processos diversas amostras de água são coletadas e analisadas em laboratório para controle e verificação das suas características (BRASIL, 2014).

De modo geral o tratamento da água consiste em: coagulação e floculação, decantação, filtração, desinfecção, correção de pH, armazenagem e distribuição, no qual, 
durante o processo de distribuição a água percorre quilômetros de tubos até o destino final (BRASIL, 2014).

Conforme o Ministério da Saúde (BRASIL, 2006), a água deve manter suas características de potabilidade na rede de distribuição até o consumidor. Contudo, durante o trajeto é possível que ocorra adversidades que podem ocasionar a contaminação da água colocando em risco a saúde da população.

Por isso, o fornecedor necessita não só tratar a água, mas também cuidar de todo processo até o cliente, realizando a manutenção da tubulação de distribuição e a realização de testes físico-químicos.

Além disso, um fator muito importante no fornecimento de qualidade da água é o manuseio intradomiciliar, ou seja, o fluxo pela instalação residencial até o armazenamento de forma a evitar a contaminação. Desse modo, é necessário realizar limpeza da caixa d'água e manutenção da tubulação a cada seis meses (BRASIL, 2018).

\section{Metodologia}

O presente trabalho, teve como ponto de partida uma pesquisa bibliográfica sobre o uso de sensores para o monitoramento da qualidade da água nas residências. Após verificar os parâmetros físicos, químicos e biológicos utilizados pela norma de potabilidade da água do Ministério da Saúde (BRASIL, 2017), decidiu-se que os principais fatores observados seriam a turbidez e a condutividade da água. Esses dois parâmetros físicos podem ser monitorados utilizando uma plataforma Arduino em conjunto com sensores de funcionamento relativamente simples que podem ser replicados com materiais de baixo custo.

A princípio estipulou-se que os sensores deveriam ser instalados em tubulações com diâmetro de três quartos de polegada, por ser o tipo de encanamento mais comum utilizado em residências. Outro fator importante, é posicioná-los em locais próximos aos hidrômetros para que a avaliação da qualidade da água seja feita antes que a água chegue ao reservatório.

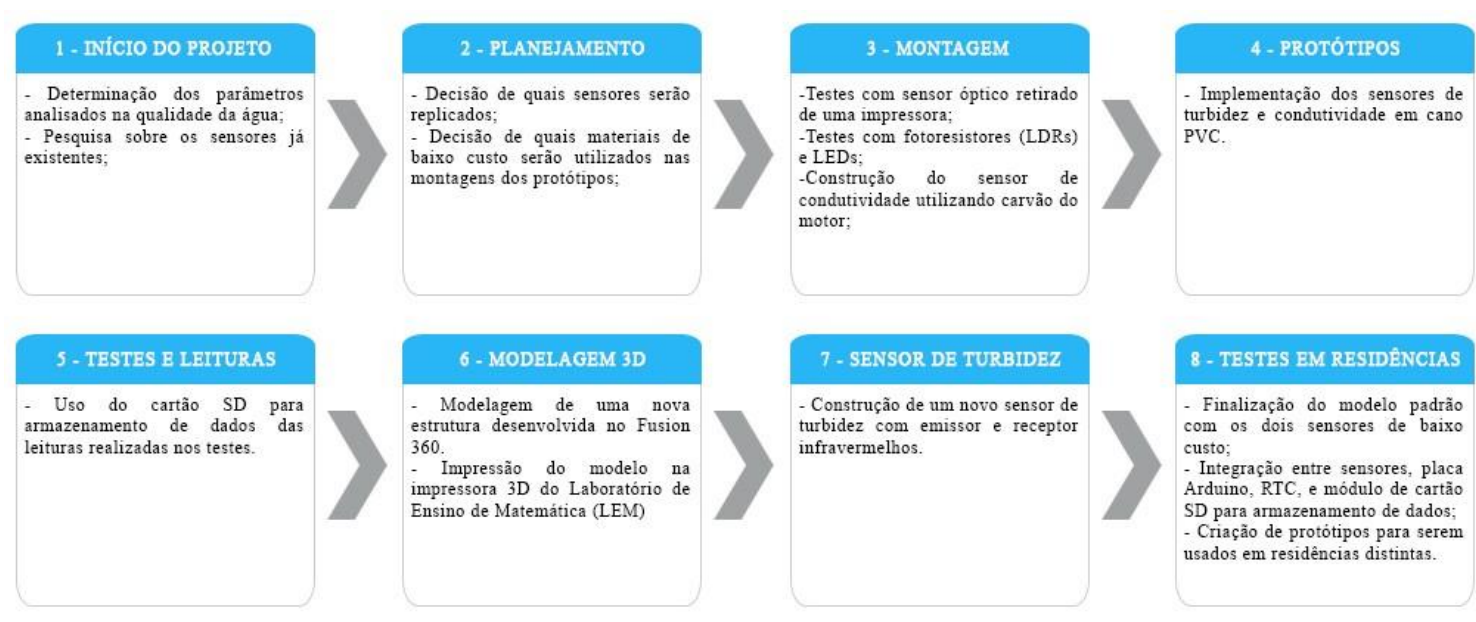

Figura 1 - Sequenciamento didático da pesquisa 
Na Figura 1 está descrita a sequência abordada no desenvolvimento do projeto em questão. Atualmente o projeto encontra-se na fase 8. Ao longo das fases de desenvolvimento, diversos protótipos e melhorias foram realizadas para uma melhor leitura dos parâmetros a serem analisados pelos sensores.

Na fase atual, o principal objetivo é o aprimoramento dos protótipos, de forma que os sensores de um mesmo tipo submetidos aos mesmos testes, obtenham uma mesma variação dentro de uma margem de tolerância em suas medidas. Uma vez verificado essa etapa, valida-se a eficiência em determinar discrepâncias nas características da água em relação às medidas que foram estabelecidas como padrão.

Serão utilizados os módulos: leitor de cartão SD e RTC (Real Time Clock). O primeiro é responsável pelo armazenamento dos dados dos sensores, já o RTC consiste em um relógio de funcionamento independente do Arduino, com bateria própria. Desse modo, ao combinar esses dois módulos o Arduino é capaz de armazenar as leituras dos sensores juntamente com seus respectivos horários. Em pouco tempo os sensores serão implementados em residências distintas para que possam ser realizados testes de campo.

\subsection{Sensor de Turbidez}

O aparelho idealizado para medir a turbidez da água, consiste em uma fonte luminosa e um sensor que detecta a intensidade da luz que incide sobre o mesmo. Estes elementos são posicionados a $180^{\circ}$ um do outro, fixados nas paredes de um tubo por onde o líquido iria fluir.

Este sensor baseia-se no fato de que as partículas dispersas na água bloqueiam parte da luz que incide nos sensores, seja esta, luz branca ou infravermelha. Dessa forma é possível realizar comparações entre a intensidade da luz captada e a turbidez do líquido.

Para o desenvolvimento do sensor, os componentes vistos na Figura 2, foram testados e analisados:

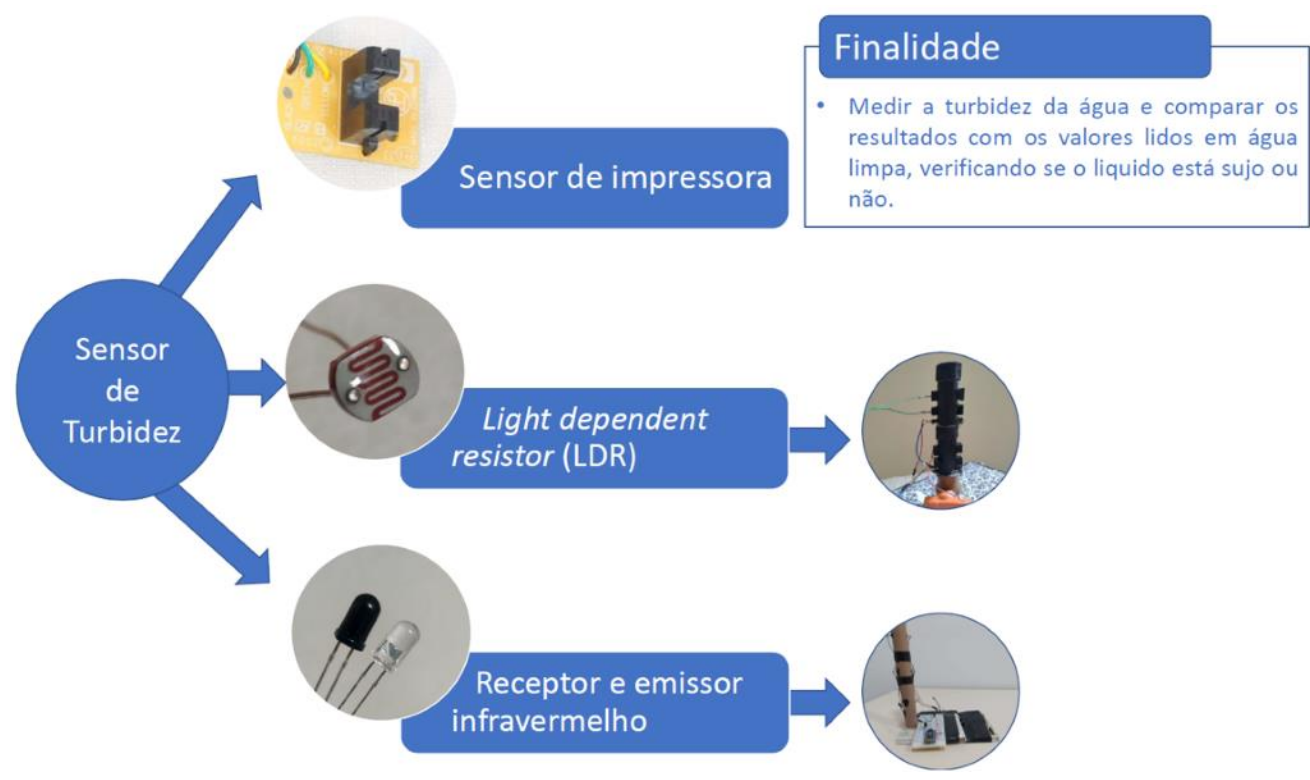

Figura 2: Versões do sensor de turbidez 
A Figura 2 ilustra os três protótipos criados com o propósito de medir a turbidez da água. O primeiro é constituído por um sensor óptico retirado de uma impressora. $\mathrm{O}$ segundo foi baseado no funcionamento de um LDR (Light Dependent Resistor), resistor que tem valor de sua resistência alterado com a intensidade de iluminação que incide sobre ele. No terceiro protótipo utilizou-se um fototransistor em conjunto com um emissor, ambos atuando na faixa infravermelha sendo este último o mais promissor. Os prós e contras de cada protótipo serão abordadas na Seção 5.1 Resultados e Discussões.

\subsection{Sensor de Condutividade}

Para a elaboração do sensor de condutividade utilizou-se duas escovas de carvão (grafite) de motor, que atuam como eletrodos. A escolha do material foi devido ao baixo risco de contaminação da água e de oxidação. Ver Figura 3:

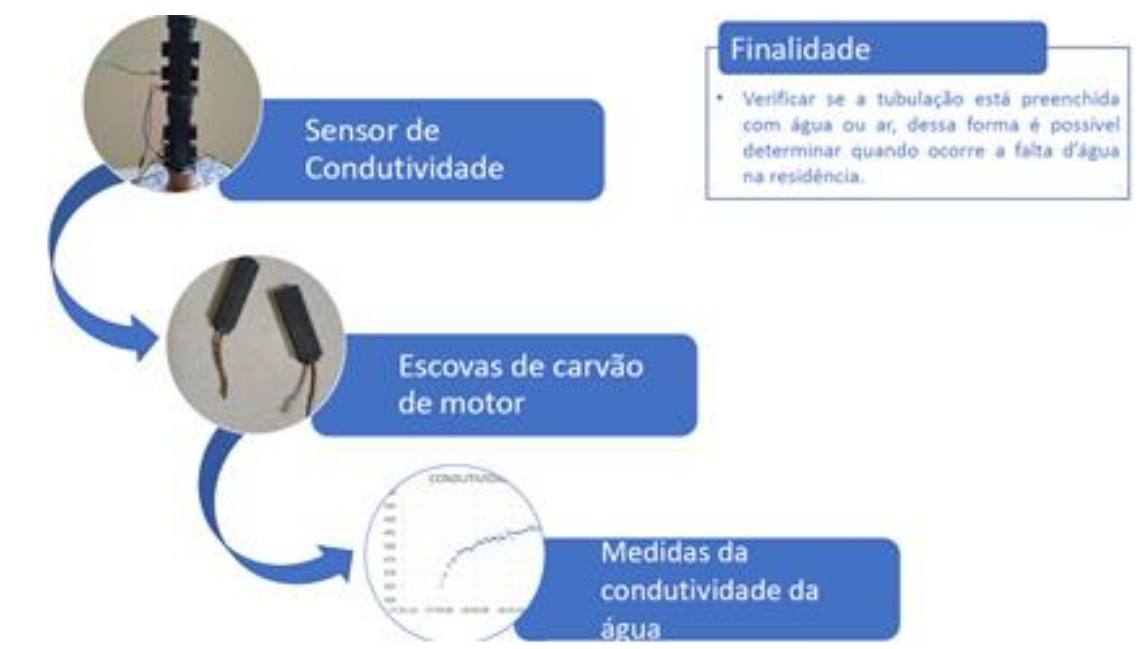

Figura 3 - Protótipo do sensor de condutividade

De acordo com a Figura 3, as escovas foram colocadas paralelamente a uma distância de $15 \mathrm{~mm}$ uma da outra para evitar o acúmulo de gotas d'água entre os carvões nos momentos em que não há líquido percorrendo a tubulação. Sendo assim, utilizando a plataforma Arduíno, é possível determinar quando o fornecimento de água é interrompido na residência.

\section{Resultados e Discussões}

\subsection{Sensor de Turbidez}

O protótipo no qual se utilizou o sensor óptico, retirado de uma impressora, mostrou diversas inconsistências em suas leituras. O sensor apresentou um desvio padrão elevado em testes com amostra única, falta de estabilidade em suas medidas e alta sensibilidade a qualquer movimento na água. No entanto, este modelo parece ser o mesmo utilizado em sensores comerciais para plataforma Arduino, o que significa que, com as devidas calibrações e com um suporte apropriado para sua imersão na água, pode ser uma alternativa interessante para a medida da turbidez. 
O segundo modelo utilizado, o LDR apresentou medidas consistentes, com desvio padrão relativamente baixo em amostras de água retiradas de uma mesma fonte. Porém, ao longo de semanas de testes repetidos os fotorresistores apresentaram queda em seu desempenho, elevando sua resistência muito acima do valor de medida descrito pelo fabricante.

O terceiro e último modelo, até o presente momento se mostrou bastante consistente em suas medidas. $\mathrm{O}$ protótipo tem seu funcionamento na faixa de radiação infravermelha e dessa forma, a luz visível não interfere no resultado, mas por outro lado, o calor pode interferir nas leituras, uma vez que este também é uma fonte de radiação infravermelha. Diante deste fato, verificou-se que o equipamento apresenta um melhor desempenho caso instalado em uma área da residência onde a temperatura da tubulação seja relativamente constante. Uma outra alternativa, seria a implementação de um sensor de temperatura acoplado ao sistema para que possa ser feita uma compensação nas medições.

\subsection{Sensor de Condutividade}

A seguir observa-se o gráfico de um dos testes utilizando o sensor de condutividade, onde foram realizadas diversas leituras de tensão com intervalos de um minuto entre cada leitura, ao longo de aproximadamente nove horas:

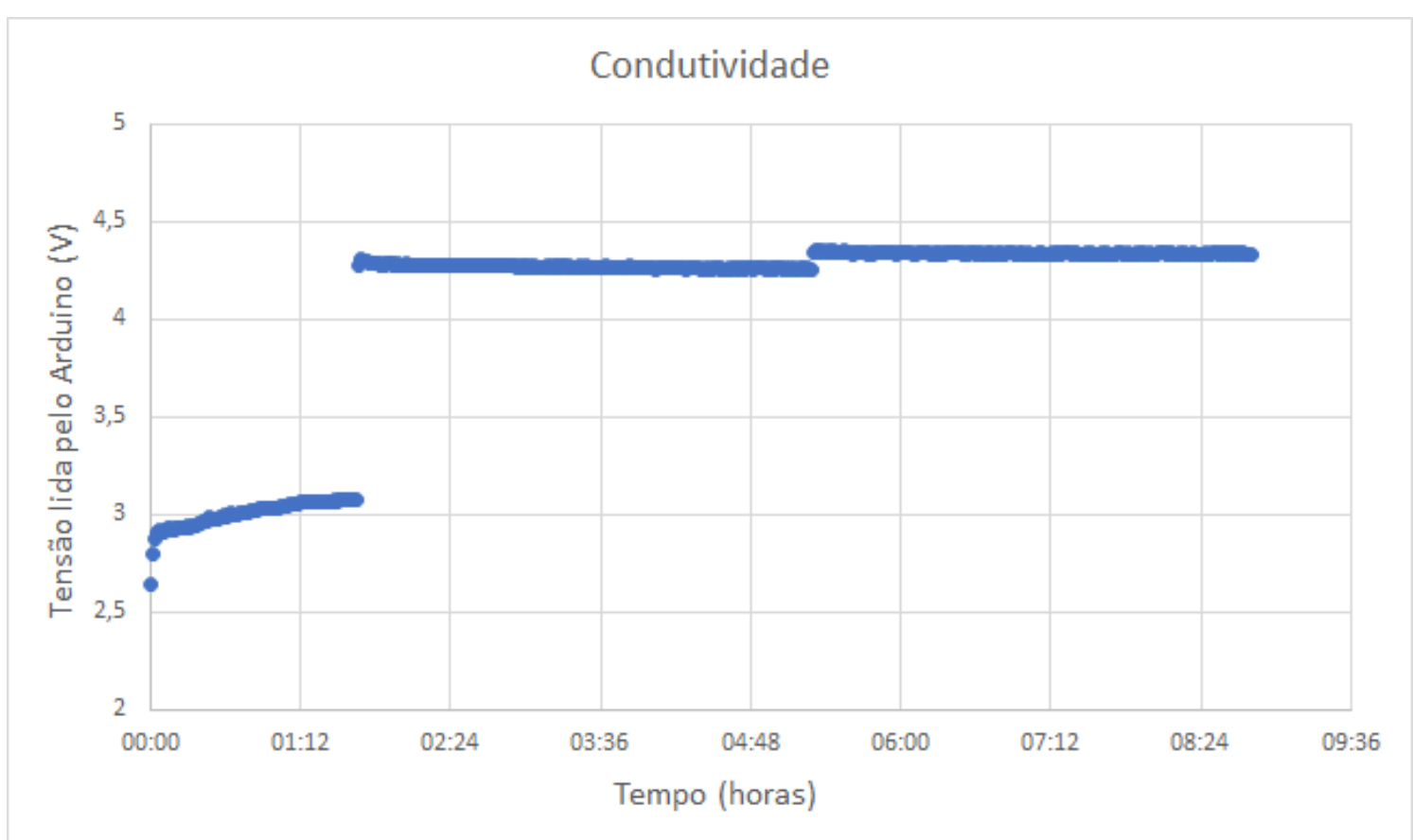

Figura 4 - Teste com sensor de condutividade

A Figura 4 mostra os dados coletados do experimento realizado durante nove horas. Foram adicionadas duas quantidades arbitrarias de sal em uma amostra de $60 \mathrm{ml}$ de água em dois momentos distintos durante esse intervalo. Esta ação refletiu em duas variações abruptas nas leituras analógicas obtidas pelo Arduino como pode ser observado no gráfico da Figura 4, onde inicialmente tem-se as medidas da água limpa. 
Ao utilizar este protótipo não foi possível identificar com precisão a condutividade da água, impossibilitando dessa forma, determinar a concentração de sólidos dissolvidos na solução. Contudo, caso fosse possível, haveria uma maneira de utilizar um gráfico de correlação entre as leituras obtidas em volts (v) no Arduino em amostras específicas, e as leituras dadas em microSiemens por centímetro $(\mu \mathrm{S} / \mathrm{cm})$ dessas mesmas amostras em um condutivímetro de bancada. Através dessa relação matemática, poderia estabelecer-se uma equação de relação entre essas duas medidas, e consequentemente o uso do sensor em qualquer outra amostra para determinação de sua condutividade.

Apesar do fato apresentado anteriormente, há possibilidade de detectar irregularidades que sejam significativas no fornecimento da água. Também é possível determinar quando existe apenas ar na tubulação, pois nesse meio não existe a passagem de corrente elétrica pelas escovas de carvão, ou seja, a tensão obtida é de zero volts. Este detalhe não foi mostrado no gráfico da Figura 4 para melhor visualização das variações que ocorrem somente em meio aquoso.

\section{Conclusões e Trabalhos Futuros}

Tendo em vista os resultados apresentados na Seção 5, observa-se que os protótipos ainda precisam ser aprimorados. Dadas as irregularidades dos materiais utilizados, será preciso desenvolver métodos de calibração para cada um dos sensores. No estágio atual da pesquisa, os modelos podem ser utilizados na detecção de irregularidades que sejam suficientemente significativas no monitoramento da qualidade da água. Há a possibilidade de comparar os resultados obtidos com os sensores de baixo custo desta pesquisa com os resultados obtidos utilizando sensores comerciais (dispositivos de laboratório). Porém, esse não é o objetivo do trabalho, uma vez que a proposta descrita neste artigo é informar ao usuário possíveis variações das características regulares da água que está sendo recebida.

O sensor de condutividade encontra-se em fase final de testes, seu desempenho até o momento mostrou-se satisfatório conforme indicado na Figura 4. O sensor é capaz de identificar quando há a presença de ar na tubulação, registrando uma tensão de zero volts devido não haver condutividade elétrica nessas condições.

O aparato para a medição da turbidez, por sua vez, possui três versões com diferentes sensores de luminosidade. Cada um apresenta seus prós e contras e necessitam de determinadas condições, para que possam identificar a diminuição da intensidade de um feixe de luz ao atravessar uma amostra de água para sua melhor eficiência.

A próxima fase da pesquisa, será a instalação dos sensores em residências conforme procedimento metodológico 8 , de forma que os dados sejam averiguados e sua eficiência comprovada. Caso haja êxito será desenvolvido o projeto de placa de circuito impresso para que o modelo possa ser replicado. Os protótipos atualmente estão em fase de aprimoramento e de testes, de forma a estabelecerem os padrões impostos pelos órgãos de normatização. A pesquisa faz parte do grupo de estudo em robótica e Arduino do Grupo PET Novas Tecnologias Voltadas para o Ensino. 


\section{Agradecimentos: FNDE, CNPq}

\section{Referências}

AGSOLVE Monitoramento Ambiental. (2013) "Como e porque medir a condutividade elétrica (CE) com sondas multiparâmetros?”

https://www.agsolve.com.br/noticias/como-e-porque-medir-a-condutividade-eletricace-com-sondas-muiltiparametros, Março.

BRASIL. Ministério da Saúde. Fundação Nacional de Saúde. (2014) "Manual de controle da qualidade da água para técnicos que trabalham em ETAS", http://www.funasa.gov.br/documents/20182/38937/Manual+de+controle+da+qualida de + da + água + para + técnicos + que + trabalham + em + ETAS +2014 .pdf/85bbdcbc-8cd24157-940b-90b5c5bcfc87, Março.

BRASIL. Ministério da Saúde. (2018) "Qualidade da água para consumo humano: Cartilha para promoção e proteção da saúde", http://bvsms.saude.gov.br/bvs/publicacoes/qualidade_agua_consumo_humano_cartil ha_promocao.pdf, Abril.

BRASIL. Ministério da Saúde. Secretaria de Vigilância em Saúde. (2006) "Vigilância e controle da qualidade da água para consumo humano", https://bvsms.saude.gov.br/bvs/publicacoes/vigilancia_controle_qualidade_agua.pdf, Abril.

BRASIL. Ministério da Saúde. (2011) "Portaria n 2.914, de 12 de dezembro de 2011 b. Dispõe sobre os procedimentos de controle e de vigilância da qualidade da água para consumo humano e seu padrão de potabilidade". https://bvsms.saude.gov.br/bvs/saudelegis/gm/2011/prt2914_12_12_2011.html, Março.

BRASIL. (2017) "Portaria de Consolidação n” 5, de 28 de setembro de 2017. Consolidação das normas sobre as ações e os serviços de Saúde do Sistema Único de Saúde", https://www.saude.gov.br/images/pdf/2018/marco/29/PRC-5-Portaria-deConsolida----o-n---5--de-28-de-setembro-de-2017.pdf, Março.

CARDOSO, Thaiany Guilherme. (2011) "Sensor de turbidez para análise de amostras de água", https://repositorio.uniceub.br/jspui/bitstream/123456789/3206/2/20663851.pdf, Março.

CPRM - Companhia de Pesquisa de Recursos Minerais. (2007) "Manual Medição in loco: Temperatura, $\mathrm{pH}$, Condutividade Elétrica e Oxigênio Dissolvido", http://www.cprm.gov.br/publique/media/gestao_territorial/geologia_medica/manual_ medicoes_T_\%20pH_OD.pdf, Março.

FILHO, Jairo Tardelli (2016). "Aspectos relevantes do controle de perdas em sistemas públicos de abastecimento de água", http://revistadae.com.br/artigos/artigo_edicao_201_n_1622.pdf, Dezembro. 
GILLETT, David; MARCHIORI, Alan. (2019). "A Low-Cost Continuous Turbidity Monitor" Sensors 19, no. 14: 3039. https://www.mdpi.com/14248220/19/14/3039\#cite

LIMA, Ellen Lima De. (2018) "Módulo de sensores para monitoramento da qualidade da água com transmissão sem fio utilizando plataforma de prototipagem". http://tede2.uefs.br:8080/bitstream/tede/863/2/Disserta\%C3\%A7\%C3\%A3o\%20\%20Ellen\%20Lima\%20de\%20Lima.pdf, Fevereiro.

MESA, Eder Daniel Ogeda et al. (2015) "Waterlife: Monitor de qualidade da Água utilizando as plataformas Android e Arduino". In: Computer on the Beach, https://siaiap32.univali.br/seer/index.php/acotb/article/view/7120/4040, Fevereiro.

MIERZWA, José Carlos. (2002) "O uso racional e o reuso como ferramentas para o gerenciamento de águas e efluentes na indústria: estudo de caso da Kodak brasileira" https://www.teses.usp.br/teses/disponiveis/3/3147/tde-14112002203535/publico/TeseJCM.pdf, Março.

OLIVEIRA, Willian Pereira de. (2015) "Desenvolvimento de turbidímetro e nefelômetro de baixo custo", http://www.eletrica.ufpr.br/p/arquivostccs/397.pdf

PALUDO, Diego. (2010) "Qualidade da água nos poços artesianos do município de Santa Clara do Sul", https://www.univates.br/bdu/bitstream/10737/458/3/DiegoPaludo.pdf, Março.

VESPERMANN, Kele C. et al. (2012) "Contaminação por coliformes totais e termotolerantes no rio Todos os Santos, Teófilo Otoni, Minas Gerais”, http://www.meioambientepocos.com.br/anais/edicoes.php, Março. 